\title{
Adolescent Leadership and Adulthood Fertility: Revisiting the "Central Theoretical Problem of Human Sociobiology"
}

\author{
Markus Jokela and Liisa Keltikangas-Järvinen \\ University of Helsinki
}

\begin{abstract}
Human motivation for social status may reflect an evolved psychological adaptation that increased individual reproductive success in the evolutionary past. However, the association between status striving and reproduction in contemporary humans is unclear. It may be hypothesized that personality traits related to status achievement increase fertility even if modern indicators of socioeconomic status do not. We examined whether four subcomponents of type-A personality-leadership, hard-driving, eagerness, and aggressiveness - assessed at the age of 12 to 21 years predicted the likelihood of having children by the age of 39 in a population-based sample of Finnish women and men $(N=1,313)$. Survival analyses indicated that high adolescent leadership increased adulthood fertility in men and women, independently of education level and urbanicity of residence. The findings suggest that personality determinants of status achievement may predict increased reproductive success in contemporary humans.
\end{abstract}

Human societies and social groups are structured by status hierarchies where, more often than not, people are trying to reach the top (Cummins, 2005; Lund, Tamnes, Mouestue, Buss, \& Vollrath, 2007; Mazur, 2005). Evolutionary psychologists have argued that human motivation for status derives from the reproductive advantage dominant individuals have enjoyed over evolutionary history. High social

This research was supported by the Academy of Finland (Grants 1111056, 77841, and 210283) and the Finnish Foundation for Cardiovascular Research. M. Jokela was supported by the Finnish Cultural Foundation and L. Keltikangas-Järvinen was supported by the Yrjö Jahnsson Foundation.

Correspondence concerning this article should be addressed to Markus Jokela, Department of Psychology, University of Helsinki, P. O. Box 9, FIN-00014, Finland. E-mail: markus.jokela@helsinki.fi.

Journal of Personality 77:1, February 2009

(C) 2008, Copyright the Authors

Journal compilation (C) 2009, Wiley Periodicals, Inc.

DOI: $10.1111 / \mathrm{j} .1467-6494.2008 .00543 . x$ 
rank has been beneficial in attracting mates and accruing resources needed for survival and taking care of offspring, so traits associated with status achievement have probably been favored by natural selection (Cummins, 2005; see Ellis, 1995). This hypothesis is supported by data from several preindustrial populations, where high social status is correlated with reproductive success, at least in men (e.g., Low, 1991; see Hopcroft, 2006).

In modern societies a person's social standing is usually assessed on the basis of socioeconomic status, that is, education, occupational status, and income. In contrast to evolutionary theorizing, the correlation between socioeconomic status and fertility in contemporary postindustrial countries appears to be absent or even negative (Vining, 1986). In other words, wealthy people are not trading their social success into reproductive success. Vining (1986) considered this to be the "central theoretical problem of human sociobiology": If evolutionary theory does not correctly predict reproductive behavior, its relevance in understanding modern human behavior more generally may be questionable.

Proponents of sociobiology and evolutionary psychology have not agreed with this conclusion. First, recent studies suggest that high social rank or economic success may, after all, increase fertility even among modern humans in some social settings (Fieder et al., 2005; Hopcroft, 2006; see also Vikat, 2004). Second, it has been argued that "counting babies" in present-day societies is not relevant to evolutionary theories of human behavior: Evolution has produced adaptations to guide behavior in the evolutionary past, but this is not to say that these mechanisms should necessarily lead people to maximize reproductive success in modern environments (Crawford, 2000; Symons, 1987). In a related vein, it has been shown that men with high status have sex more frequently than men with low status (Kanazawa, 2003; Pérusse, 1993). Increased sexual access would have conferred reproductive advantage in the evolutionary past but may not do so in modern environments with effective contraceptive methods.

Here we wish to test a hypothesis that has received little attention in previous research on status and reproduction. Natural selection has obviously not been acting on social status per se because status is a position achieved over the life course in a social environment, not something inherited in genes. Rather, natural (or sexual) selection may have favored heritable individual characteristics that have 
increased the probability of attaining status in social groups. We hypothesized that such individual characteristics are still positively associated with fertility even if socioeconomic status is not. Here we tested this hypothesis in the context of personality.

\section{Present Study}

We examined whether subcomponents of adolescent type-A personality predicted fertility in adulthood 18 years later in the populationbased epidemiological Cardiovascular Risk in Young Finns study (Åkerblom et al., 1991). Type-A personality is a multifaceted personality trait expressed as high competitiveness, achievement striving, impatience, and irritability. The Hunter-Wolf Scale of type-A behavior (Wolf, Sklov, Wenzl, Hunter, \& Berenson, 1982) used here includes four subscales: leadership, responsibility, eagerness, and aggression (Ravaja, Keltikangas-Järvinen, \& Keskivaara, 1996). Different components of type-A behavior have different social and health consequences (e.g., Keltikangas-Järvinen, 1992; MacEwen \& Barling, 1993; Ovcharchyn, Johnson, \& Petzel, 1981; Ravaja et al., 1996; Wolf et al., 1982). Here we were primarily interested in the components associated with achievement and status striving, that is, leadership and responsibility, rather than those related to impatience, irritability, and stress, that is, eagerness and aggression.

Social status may be important for reproductive success in men, but the role of status in women's reproductive success has received less attention. Studies on nonhuman primates do indicate that social status may be relevant for female reproductive success (Pusey, Williams, \& Goodall, 1997), but empirical evidence for humans is scarce. On the other hand, being a mother and striving for status are sometimes perceived as opposite tendencies, at least in modern Western cultures, as women may have difficulties in combining career advancement and family formation (see Brewster \& Rindfuss, 2000; cf. Deady \& Smith, 2006). If women's status striving were strongly associated with pursuit of socioeconomic goals, it might lead to lower rather than higher fertility.

Other sociodemographic factors besides education may be relevant to fertility behavior. Having a spouse naturally increases the likelihood of having children. We therefore assessed whether the association between type-A personality and fertility was mediated by marital status across the life course. Furthermore, fertility rates in 
Finland tend to be higher among rural than urban dwellers, although this difference has decreased over recent decades (Koskinen, Jalovaara, \& Martelin, 2007). Given that type-A personality has been associated with urban living (Espnes \& Mellam, 2001), we included residential location as a covariate.

In sum, we hypothesized a positive association between adolescent type-A personality subcomponents reflecting status striving, that is, leadership and responsibility, and high adulthood fertility in men. In women we tested two competing hypotheses, one suggesting a positive and the other a negative association between adolescent type-A personality and adulthood fertility. We also examined if the association between type-A personality and fertility was accounted for by differences in marital status across the follow-up period.

\section{METHOD}

\section{Participants}

The participants were 1,313 women $(n=740)$ and men $(n=573)$ participating in the on-going population-based study Cardiovascular Risk in Young Finns (Åkerblom et al., 1991; Raitakari et al., 2003). In this epidemiological study a randomly selected sample of 3,596 Finnish healthy children and adolescents from six birth cohorts (aged 3, 6, 9, 12, 15, and 18 years at the baseline) has been followed since 1980. Finland was divided into five areas according to location of university cities with a medical school (Helsinki, Kuopio, Oulu, Tampere, and Turku), and urban and rural boys and girls from each area were randomly selected on the basis of their personal social security number from a national population register. Three years after the baseline, participants of the four oldest cohorts were administered the Hunter Wolf A-B Rating Scale (Wolf et al., 1982). Thus, the participants of the present study were $12,15,18$, and 21 years of age at the time of personality assessment (here referred to as Year 0 ), and $30,33,36$, and 39 years at the final follow-up phase (18 years after the personality assessment, referred to as Year 18).

A multivariate logistic regression analysis of attrition indicated that men $(O R=1.45, S E=.19, \quad p=.0015)$ and younger participants $(O R=.94, S E=.02, p=.006)$ were more likely to drop out of the study between years 0 and 18 than women and older participants. Leadership, aggression, and responsibility did not predict attrition ( $p$ values $>.16$ ) whereas high eagerness-energy decreased the probability of drop out $(O R=.96, S E=.01, p=.009)$, so that eagerness 
$1 S D$ above the mean decreased the probability by $2 \%$, that is, from $19 \%$ to $17 \%$.

\section{Measures}

Type-A personality was assessed on the Hunter Wolf A-B Rating Scale (Wolf et al., 1982), a self-administered questionnaire consisting of 23 items ranked on a 7-point scale (one of the original items referring to school behavior was dropped because not all participants attended school at the time of assessment). Items of the Hunter-Wolf Scale comprise two opposing statements reflecting contrasting behavior, such as "I like to argue-I don't like to argue." The scale has previously (Ravaja et al., 1996; Wolf et al., 1982) been shown to have four subcomponents: Leadership (six items; I always take charge of things, My peers always choose me to be a leader in various activities, I always want to win, I like to tell others what to do, I have many hobbies, I am interested in many things; Cronbach's $\alpha=.65$ ), Responsibility (three items; I am hard-driving, It bothers me if I am late, I take things seriously; $\alpha=.64$ ), Aggression (seven items; It takes very little to get me angry, I tend to get into fights easily, I often interrupt when someone else is talking, I find it difficult to wait, I talk loud, I like to argue with others, I lose my temper easily; $\alpha=.68$ ), and Eagerness-Energy (seven items; I am always in a hurry, I walk with a fast pace, I think time often passes quickly, I talk fast, I eat fast, I think about many things at the same time, I drink fast; $\alpha=.56$ ). The reliabilities of the subscales were acceptable although somewhat low, which may reflect the relatively young age of the participants. Table 1 shows the descriptive statistics and intercorrelations of the subscales.

\section{Table 1}

Correlations and Descriptive Statistics of Type-A Personality Subscales $(N=1,313)$

\begin{tabular}{lcccc}
\hline & Leadership & Responsibility & Aggression & Eagerness \\
\hline Leadership & 1.00 & & & \\
Responsibility & 0.10 & 1.00 & & \\
Aggression & 0.14 & -0.11 & 1.00 & \\
Eagerness & 0.27 & 0.09 & 0.27 & 1.00 \\
Mean (SD) men & $26.2(5.3)$ & $14.0(3.2)$ & $26.2(6.1)$ & $32.5(5.0)$ \\
Mean (SD) women & $25.0(5.5)$ & $14.9(3.1)$ & $27.7(6.6)$ & $33.3(4.8)$ \\
\hline
\end{tabular}

Note: All correlations and mean gender differences were statistically significant $(p<.01)$. 
In Year 18 the participants reported the number of children they had and the years of their births. The age of the participant at the birth of the first, second, and third child was determined from these data. A timevarying covariate describing marital history was created for each year on the basis of marital status data the participants have provided in followup phases in years 3, 6, 9, and 18. In Years 9 and 18 the participants also reported how long they had occupied their current marital status. Missing values were replaced with data from the previous year. This procedure resulted in a time-varying marital status variable with an accuracy of approximately 3 years. Marital status was coded as a dichotomous indicator $(0=$ not living with a partner, $1=$ living with a partner, i.e., married or cohabiting) in each year.

Another indicator of marital history was created to be used as a dependent variable in a linear regression analysis when assessing whether Year 0 personality predicted later marital status. We created a cumulative measure of marital status by summing together marital status $(0=n o t$ living with a partner, $1=$ living with a partner) in follow-up phases in Years $3,6,9$, and 18. This resulted in a cumulative measure of marriage/ cohabitation with a range from 0 to 4 (mean $=1.84, S D=1.32$ ).

Year 18 level of education was assessed on a 7-point scale ranging from compulsory school (1) to university degree (7). Urbanicity of residence was used as a time-varying covariate. In Years $0,3,6$, 9, and 18 the participants reported their current type of residence on a 4-point scale $(1=$ city; $2=$ suburban area $; 3=$ rural area $; 4=$ remote rural area). A continuous time-varying covariate of residence was created in the same way as the time-varying marital status covariate (see above).

\section{Statistical Analysis}

Discrete-time survival analysis was applied to examine whether and when the participants had their first, second, and third child and whether the subscales of adolescent type-A personality predicted these events. The birth of the fourth or any subsequent child was not examined because only 92 participants $(5.2 \%)$ had a fourth child and $26(1.5 \%)$ had five or more children. At the time of personality assessment, 31 participants had already had the first child and 1 participant the second child, and none had a third child. To have a completely prospective study design, these left-truncated cases were excluded from the respective analyses, that is, the birth of the $n$th child was assessed only in those who did not have the $n$th child at the time of the personality assessment.

We used the participant's age as the measure of time. Age-specific fertility is known to follow a bell-shaped curve, so linear and quadratic terms of time were included into the models. In survival analysis a participant is 
censored either when the event of interest occurs (i.e., a child is born) or when the study period ends (i.e., at the age of $30,33,36$, or 39 depending on the cohort the participant belonged to). The survival analyses thus allowed us to estimate the probabilities of having the first, second, and third child by the age of 39 .

Given the potential gender-specific nature of social status and reproduction, we fitted all the models separately for women and men. Age, education, place of residence, and marital status were entered as covariates. Completed education was used as a time-invariant covariate, and place of residence and marital status were used as time-varying covariates. The models were fitted in four steps: first with only personality trait, then with Time $\times$ Personality interaction, after which we controlled for education and place of residence, and finally controlling for marital status. The results were illustrated by calculating and plotting the hazard functions and cumulative probabilities of having the first, second, and third child by different levels of personality scores ranging from $2 S D$ below to $2 S D$ above the mean level. In these predictions other covariates were assigned their mean values. The association between personality and education and cumulative marital status measure was assessed with linear regression analysis, controlling for age.

\section{RESULTS}

First we assessed the role of covariates in predicting fertility in survival analysis models. High education was associated with decreased likelihood of having children in the survival analysis models, particularly in women (first child: $B=-.15, S E=.02, p<.001$; second child: $B=-.12, S E=.03, p<.001$; third child: $B=-.13, S E=.04$, $p=.004$ ) and to some extent also in men (First: $B=-.07, S E=.03$, $p=.02$; second: $B=-.05, S E=.03, p=.15$; Third: $B=-.11$, $S E=.06, p=.07)$. In men, rural residence was not associated with birth of the first $(B=-.03, S E=.05, p=.53)$ or second $(B=.00$, $S E=.06, p=.90)$ child, but tended to predict the third child $(B=.17, S E=.09, p=.08)$. In women, rural residence increased fertility (first: $B=.07, S E=.04, p=.08$; second: $B=.13, S E=.05$, $p=.004$; third: $B=.19, S E=.07, p=.008)$. Having a partner increased fertility in women (first: $B=2.13, S E=.11, p<.001$; second: $B=2.53, S E=.18, p<.001$; third: $B=2.06, S E=.30, p<.001)$ and in men (first: $B=2.23, S E=.12, p<.001$; second: $B=1.99$, $S E=.17, p<.001$; third: $B=2.47, S E=.42, p<.001)$. 


\section{Table 2}

Predicting Fertility by Adolescent Leadership: Separate Nested Survival Analysis Models for the Birth of the First, Second, and Third Child in Men and Women [B (SE)]

\begin{tabular}{|c|c|c|c|c|}
\hline & Step 1 & Step 2 & Step 3 & Step 4 \\
\hline \multicolumn{5}{|l|}{$\operatorname{Men}(n=573)$} \\
\hline \multicolumn{5}{|l|}{ First child } \\
\hline Leadership & $.023 *(.011)$ & $-.10(.08)$ & $.025 *(.011)$ & $.022 *(.011)$ \\
\hline Leadership $\times$ Age & & $.005^{\dagger}(.003)$ & - & - \\
\hline \multicolumn{5}{|l|}{ Second child } \\
\hline Leadership & $.018(.013)$ & $.030(.10)$ & $.022^{\dagger}(.013)$ & $.015(.013)$ \\
\hline Leadership $\times$ Age & & $-.000(.003)$ & - & - \\
\hline \multicolumn{5}{|l|}{ Third child } \\
\hline Leadership & $.033(.023)$ & $.085(.216)$ & $.040^{\dagger}(.023)$ & $.029(.023)$ \\
\hline Leadership $\times$ Age & & $-.002(.007)$ & - & - \\
\hline \multicolumn{5}{|l|}{ Women $(\mathrm{n}=740)$} \\
\hline \multicolumn{5}{|l|}{ First child } \\
\hline Leadership & $.001(.008)$ & $-.116 *(.05)$ & $-.115 *(.054)$ & $-.097^{\dagger}(.055)$ \\
\hline Leadership $\times$ Age & & $.004 *(.002)$ & $.005 *(.002)$ & $.004^{\dagger}(.002)$ \\
\hline \multicolumn{5}{|l|}{ Second child } \\
\hline Leadership & $.002(.010)$ & $-.156^{*}(.071)$ & $-.157 *(.072)$ & $-.146^{*}(.073)$ \\
\hline Leadership $\times$ Age & & $.006 *(.002)$ & $.006 *(.003)$ & $.005 *(.003)$ \\
\hline \multicolumn{5}{|l|}{ Third child } \\
\hline Leadership & $.022(.015)$ & $-.311^{* *}(.117)$ & $-.319 * *(.119)$ & $-.326^{* *}(.121)$ \\
\hline Leadership $\times$ Age & & $.011 * *(.004)$ & $.012 * *(.004)$ & $.012 * *(.004)$ \\
\hline
\end{tabular}

Note: Steps 1 and 2 adjust for age and age ${ }^{2}$. Step 3 adjusts for age, age ${ }^{2}$, residence, and education. Step 4 adjusts for age, age ${ }^{2}$, residence, education, and marital status. ${ }^{\dagger} p<.10, * p<.05, * * p<.01$.

We then assessed the association between leadership and fertility (Table 2). In the first step, leadership predicted increased fertility in men but not in women. However, there were significant Leadership $\times$ Time interaction effects in women when predicting the first, second, and third child, indicating that the relation between women's leadership and fertility was dependent on age (Step 2, see below). In a linear regression analysis high adolescent leadership predicted higher education in men $(B=.05, S E=.01, \beta=.15, p<.001)$ and women $(B=.10, S E=.01, \beta=.30, p<.001)$, the association being 
significantly stronger in women (Gender $\times$ Leadership interaction $p=.01$ ). Leadership was not related to urbanicity of Year 0 residence in men or women ( $p$ values $>.63$ ). In the survival analysis, controlling for education and place of residence did not change the association between leadership and fertility (Step 3).

Figures 1 and 2 illustrate the association between leadership and fertility in men and women, respectively. We calculated the predicted hazard functions (i.e., the probability of having a child at a given age) and cumulative fertility functions of having the first, second, and third child by a given age (i.e., $P=1-$ value of survival function)

Hazard function
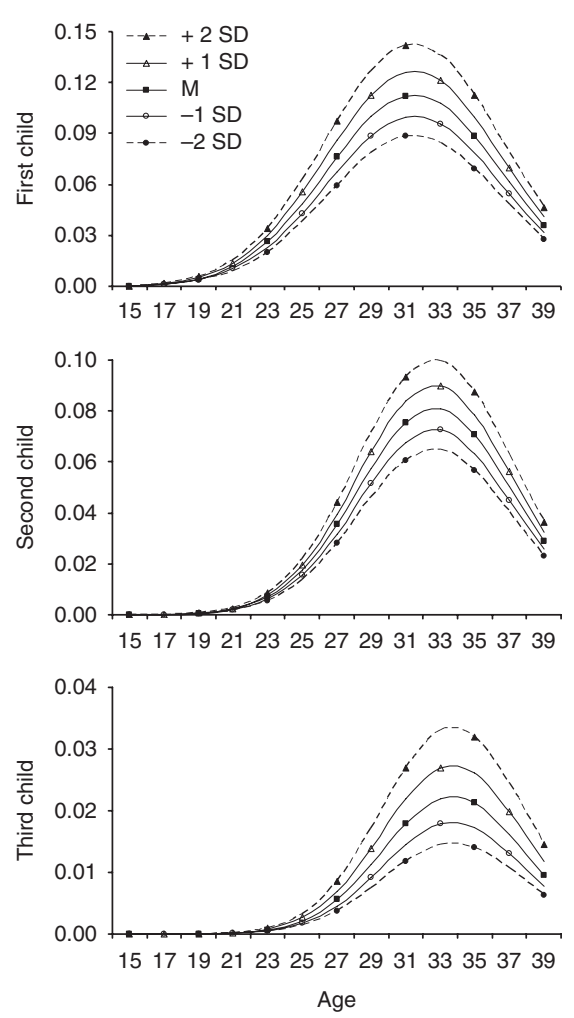

Cumulative fertility function
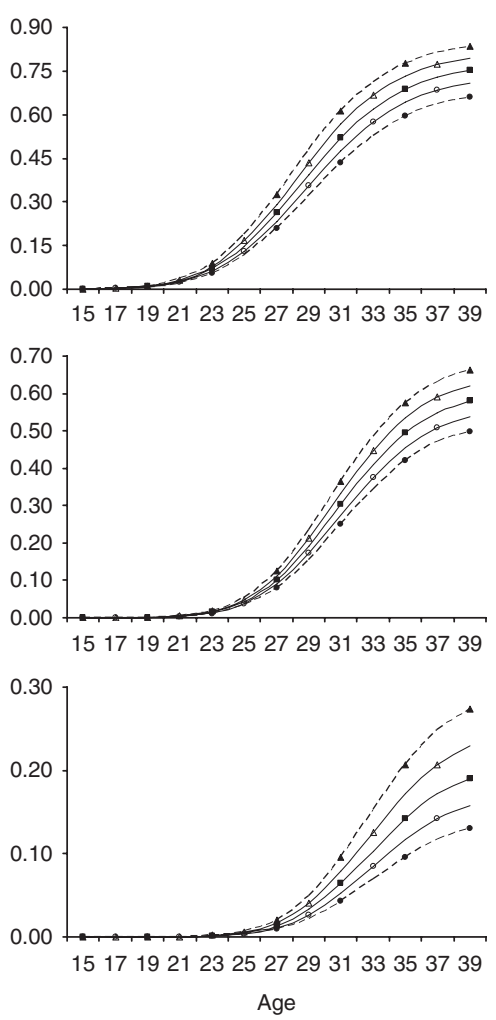

Figure 1

Men's predicted hazard functions and cumulative fertility functions (i.e., 1-survival function) of having the first, second, and third child by adolescent leadership (from $-2 S D$ to $+2 \mathrm{SD}$ ). 
Hazard function
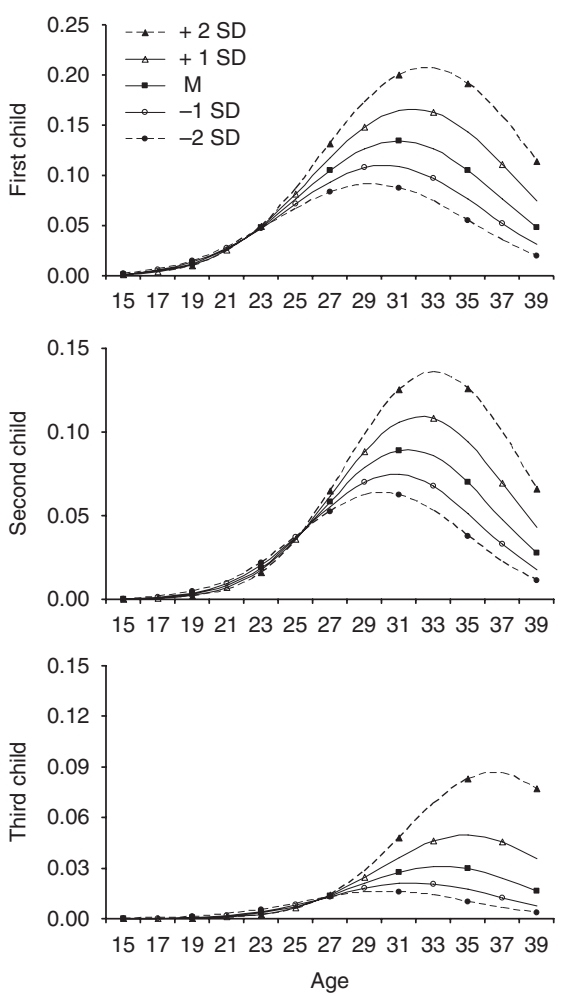

Cumulative fertility function
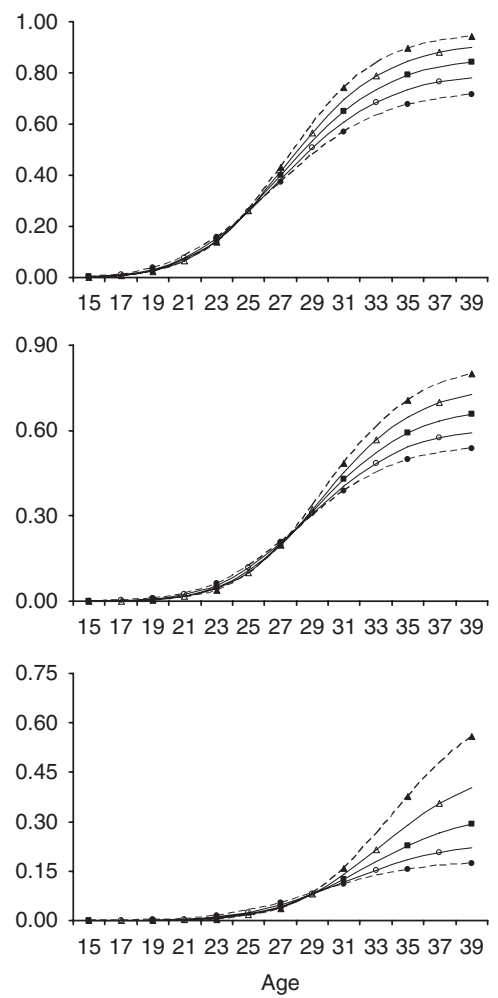

Figure 2

Women's predicted hazard functions and cumulative fertility functions (i.e., 1-survival function) of having the first, second, and third child by adolescent leadership (from $-2 S D$ to $+2 S D$ ).

by different levels of leadership, controlling for education and residence (Step 3). Men with high adolescent leadership had a higher probability of having children at any given age (Figure 1). In women, the role of leadership increased with age: Women with high leadership were more likely to continue having children after the age of 30 than their counterparts with low leadership, among whom the hazard functions began to decrease earlier (Figure 2).

Table 3 shows in numerical form the predicted cumulative probabilities of having children by the age of 39 by adolescent leadership level. In men an increase of $1 S D$ of leadership increased the probability of having children by approximately $4 \%$. In terms of 
Table 3

The Predicted Probability of Having the First, Second, and Third Child by the Age of 39 (i.e., $P=1$ - Value of Survival Function at 39) by Leadership

\begin{tabular}{llllll}
\hline & \multicolumn{5}{c}{ Leadership } \\
\cline { 2 - 6 } & $-2 S D$ & $-1 S D$ & Mean & $+1 S D$ & $+2 S D$ \\
\hline Men & & & 0.75 & 0.79 & 0.83 \\
$\quad$ First child & 0.66 & 0.71 & 0.75 & 0.62 & 0.66 \\
Second child & 0.50 & 0.54 & 0.58 & 0.23 & 0.27 \\
$\quad$ Third child & 0.13 & 0.16 & 0.19 & & \\
Women & & & & 0.90 & 0.94 \\
$\quad$ First child & 0.72 & 0.78 & 0.84 & 0.73 & 0.80 \\
Second child & 0.54 & 0.59 & 0.66 & 0.40 & 0.56 \\
$\quad$ Third child & 0.17 & 0.22 & 0.29 & & \\
\hline
\end{tabular}

percentages, that is, relative ratios of percentage points, $1 S D$ was associated with $6 \%, 7 \%$, and $20 \%$ increased probability of having the first, second, and third child, respectively. In women $1 S D$ of leadership increased the probability of having the first, second, and third child by approximately $6 \%, 7 \%$, and $11 \%$, respectively. The corresponding percentages were $7 \%, 11 \%$, and $38 \%$. Averaged over the three births, $1 S D$ of leadership increased the probability of having children by $11 \%$ in men and by $19 \%$ in women.

We then assessed whether leadership predicted marital status and if this association accounted for the association between leadership and fertility. A linear regression analysis indicated that leadership increased the cumulative likelihood of living with a partner in women $(B=.03, S E=.01, \beta=.11, p<.001)$ but not in men $(B=.01, S E=.01, \beta=.04, p=.31)$. Controlling for time-varying marital status did not substantially alter the association between leadership and fertility in women (Table 2, Step 4). In men, leadership still predicted the birth of the first child when marital status was controlled for but did not significantly predict the birth of the second and third child.

The other subscales of type-A behavior, that is, responsibility, eagerness, and aggression, did not predict fertility ( $p$ values $>.19$ ), except for eagerness and aggression, which tended to predict 
increased likelihood of having the first child in men (Eagerness: $B=.024, \quad S E=.011, p=.03$; Aggression: $B=.017, S E=.009$, $p=.07)$. However, these association were not significant $(p=.12$, $p=.14$ ) when leadership was controlled for, suggesting that leadership was the only subscale that consistently predicted fertility. Hence, the results for responsibility, aggression, and eagerness are not presented in detail.

\section{DISCUSSION}

The present findings add new evidence to the study of personality, social status, and fertility. Contemporary Finnish adolescents-both men and women - with high leadership personality were more likely to have children by the age of 39 than their counterparts with low leadership. Averaged over the birth of the first, second, and third child, $1 S D$ of leadership increased the probability of having children by $11 \%$ in men and by $19 \%$ in women. Adolescent leadership also predicted higher completed education level and, in women, increased the likelihood of living with a partner across the life course. However, the relation between leadership and fertility was independent of education and marital status, although controlling for marital status did partly attenuate the association between leadership and fertility in men.

Leadership was the only one of the four subscales of type-A behavior that consistently predicted fertility in men and women. Individuals with high leadership prefer to take charge of things, are eager to win in competitions, and tend to be selected as leaders by their peers. Hence, leadership is the type-A behavior subscale most directly associated with status striving and social dominance. This is in line with our hypothesis that the status-striving component of typeA behavior is more relevant to fertility differences than the stress component. The positive association between leadership and fertility implies that personality dispositions related to status achievement may be associated with increased fertility in modern societies even if high socioeconomic status may not be.

Social status and personal characteristics related to status achievement appear to be important determinants of men's attractiveness to women across cultures (Buss, 1989; Feingold, 1992). Men's social rank has also been associated with increased number of children in 
some modern social settings (Fieder et al., 2005; Hopcroft, 2006). Based on the present findings, we suggest that men's personal characteristics predicting status achievement may be more important determinants of reproductive success than manifestations of socioeconomic status, for example, an educational diploma or a prestigious occupation. Perhaps women (and other men) are more sensitive to face-to-face dominance relationships than to modern socioeconomic hierarchies in the context of reproductive behavior (see Mazur, 2005, for discussion on different types of dominance structures). This implies that the role of social status in mating and reproductive behavior needs to be studied simultaneously with individual characteristics predicting status achievement, so that their relative importance can be evaluated.

High adolescent leadership was associated with increased fertility in women. More specifically, an age-dependent interaction effect indicated that women with high leadership were more likely to continue having children after the age of 30 than their counterparts with low leadership, independent of education level. In other words, women's leadership was associated with late rather than early reproduction. The positive association between leadership and fertility in women contradicts the view of motherhood and status striving as opposite phenomena and instead suggests that the two may share common personality determinants. In fact, leadership differences created even greater fertility differences among women than they did among men. Leadership was also a stronger predictor of education level and marital status in women than in men, suggesting that leadership differences may have a more extensive role in women's social behavior.

The association between leadership personality and fertility suggests a positive natural selection for this dimension of personality. The evolutionary relevance of personality variation has received detailed attention only recently (Buss \& Greiling, 1999; Dingemanse \& Réale, 2005; Penke, Denissen, \& Miller, 2007; Sih, Bell, \& Johnson, 2004). Although theoretical work (e.g., Miller, 2000; Penke et al., 2007) has provided several possible evolutionary models for the existence of personality variation, it is yet beyond the present data to evaluate their plausibility with respect to leadership personality. However, we believe that these models can be used to generate further hypotheses to investigate the role of status striving in human reproductive fitness. 
Obviously, having children in modern postindustrial societies involves contextual factors absent in human evolutionary history, and it is quite possible that the present findings reflect contemporary social dynamics and structures rather than mechanisms of an evolved mind. Although these alternatives need not be mutually exclusive, we suggest that their plausibility can be evaluated in future research by identifying the proximate mechanisms mediating the association between leadership and fertility: Evolutionary explanations are supported if these mechanisms are related to evolutionary psychological adaptations, for example, mating strategies. Nonevolutionary explanations are supported if the proximate mechanisms turn out to be related to modern social circumstances not associated with psychological adaptations, for example, how individuals manage the conflict between career and family life.

There is some evidence to suggest that leadership might play a role in the social psychology of family formation. In a study of women living in the mid-20th century United States, Elder and MacInnis (1983) found that the personality trait " need for achievement" correlated positively with the number of children in women who were oriented toward domestic life. In a similar sample of women, Roberts and Bogg (2004) found that conscientiousness - a personality trait related to social responsibility, dutifulness, and achievement striving - was associated with increased number of children. In other words, personality traits related to achievement striving may become expressed in family life as well as in the labor market. A similar social phenomenon might contribute to the present association between leadership and fertility in women and men. Perhaps the idea of having children is most attractive (or least frightening) to individuals who prefer to act as leaders and to influence other people, including their own offspring.

The association between personality and fertility also needs to be interpreted within its societal context because countries differ in their family policies affecting fertility rates (Chenais, 1996). As a Nordic welfare country, Finland provides relatively generous public support to families with children, supporting the combination of career advancement and family formation (see Rønsen, 2004; Vikat, 2004). This may contribute to the positive association between leadership and fertility, particularly in women; leadership predicted increased fertility even if it predicted higher educational achievement. Whether personality traits related to social dominance and status striving 
increase (or decrease) fertility in countries with different family policies remains to be empirically tested.

The methodological strengths of our study include a prospective longitudinal study design and a population-based sample. The main limitation of the study is that personality assessment was based only on self-reports. Self-reported measures of personal dispositions may provide only a limited indicator of social dominance, which is linked to social dynamics as well as to individual dispositions (Chase, Tovey, Spangler-Martin, \& Manfredonia, 2002). Future studies should apply more diverse assessment of status striving and achievement, for example, peer nominations, in order to overcome this limitation. Furthermore, the measure of marital status only assessed marriage and cohabitation. Further research on the role of other dimensions of marital relations, for example, the number of partners and relationship satisfaction, is clearly needed.

In conclusion, contemporary Finnish men and women with high leadership personality may be more likely to have children than those with low leadership. The finding implies that relatively stable personal characteristics related to status achievement may be more relevant to evolutionary hypotheses of mating and reproductive success than indicators of socioeconomic status. Moreover, we suggest that "counting babies" may offer a relevant approach to evaluating evolutionary theories of human behavior if these observations can be integrated with other evidence pertaining to evolutionary adaptations. Finally, even if evolutionary theorizing turned out to be irrelevant in understanding modern reproductive patterns, our study indicates that personality psychology may illuminate the nature of fertility behavior in contemporary women and men.

\section{REFERENCES}

Åkerblom, H.K, Uhari, M., Personen, E., Dahl, M., Kaprio, E. A., Nuutinen, E. M., et al. (1991). Cardiovascular risk in young Finns. Annals of Medicine, 23, 35-40.

Brewster, K. L., \& Rindfuss, R. R. (2000). Fertility and women's employment in industrialized countries. Annual Review of Sociology, 26, 271-296.

Buss, D. M. (1989). Sex differences in human mate preferences: Evolutionary hypotheses tested in 37 cultures. Behavioral and Brain Sciences, 12, 1-49.

Buss, D. M., \& Greiling, H. (1999). Adaptive individual differences. Journal of Personality, 67, 209-243. 
Chase, I. D., Tovey, C., Spangler-Martin, D., \& Manfredonia, M. (2002). Individual differences versus social dynamics in the formation of animal dominance hierarchies. Proceedings of the National Academy of Sciences, USA, 99, 5744-5749.

Chenais, J. C. (1996). Fertility, family, and social policy in contemporary western Europe. Population and Development Review, 22, 729-739.

Crawford, C. (2000). Evolutionary psychology: Counting babies or studying information-processing mechanisms. Annals of the New York Academy of Sciences, 907, 21-38.

Cummins, D. (2005). Dominance, status, and social hierarchies. In D. M. Buss (Ed.), The handbook of evolutionary psychology (pp. 676-697). Hoboken, NJ: Wiley.

Deady, D. K., \& Smith, M. J. L. (2006). Height in women predicts maternal tendencies and career orientation. Personality and Individual Differences, 40, 17 25.

Dingemanse, N. J., \& Réale, D. (2005). Natural selection and animal personality. Behaviour, 142, 1165-1190.

Elder, G. H., \& MacInnis, D. J. (1983). Achievement imagery in women's lives from adolescence to adulthood. Journal of Personality and Social Psychology, 45, 394-404.

Ellis, L. (1995). Dominance and reproductive success among nonhuman animals: A cross-species comparison. Ethology and Sociobiology, 16, 257-333.

Espnes, G. A., \& Mellam, A. C. (2001). The Type A/B behaviour pattern in samples of urban and rural men. Psychological Reports, 88, 23-27.

Feingold, A. (1992). Gender differences in mate selection preferences: A test of the parental investment model. Psychological Bulletin, 112, 125-139.

Fieder, M., Huber, S., Bookstein, F. L., Iber, K., Schäfer, K., \& Winckler, G., et al. (2005). Status and reproduction in humans: New evidence for the validity of evolutionary explanations on basis of a university sample. Ethology, 111, 940-950.

Hopcroft, R. L. (2006). Sex, status, and reproductive success in the contemporary United States. Evolution and Human Behavior, 27, 104-120.

Kanazawa, S. (2003). Can evolutionary psychology explain reproductive behavior in the contemporary United States? The Sociological Quarterly, 44, 291-302.

Keltikangas-Järvinen, L. (1992). Type A behaviour and school achievement. European Journal of Personality, 6, 71-81.

Koskinen, S., Jalovaara, M., \& Martelin, T. (2007). Suomen väestö [Finnish population]. Helsinki: Gaudeamus.

Low, B. S. (1991). Occupational status, land ownership, and reproductive behavior in 19th century Sweden: Tuna Parish. American Anthropologist, 92, 115126.

Lund, O. C. H., Tamnes, C. K., Mouestue, C., Buss, D. M., \& Vollrath, M. (2007). Tactics of hierarchy negotiation. Journal of Research in Personality, 41, $25-44$.

MacEwen, K., \& Barling, J. (1993). Type A behavior and marital satisfaction: Differential effects of achievement striving and impatience/irritability. Journal of Marriage and Family, 55, 1001-1010. 
Mazur, A. (2005). Biosociology of dominance and deference. Lanham, MD: Rowman \& Littlefield.

Miller, G. F. (2000). Mental traits as fitness indicators: Expanding evolutionary psychology's adaptationism. In D. LeCroy \& P. Moller (Eds.), Evolutionary perspectives on human reproductive behavior (pp. 62-74). New York: New York Academy of Sciences.

Ovcharchyn, C. A., Johnson, H. H., \& Petzel, T. P. (1981). Type A behavior, academic aspirations, and academic success. Journal of Personality, 49, 248256.

Penke, L., Denissen, J. J. A., \& Miller, G. F. (2007). Evolution, genes, and interdisciplinary personality research. European Journal of Personality, 21, 639-665.

Pérusse, D. (1993). Cultural and reproductive success in the industrial societies: Testing the relationship at the proximate and ultimate levels. Behavioral and Brain Sciences, 16, 267-322.

Pusey, A., Williams, J., \& Goodall, J. (1997). The influence of dominance rank on the reproductive success of female chimpanzees. Science, 277, 828-831.

Raitakari, O. T., Juonala, M., Kahonen, M., Taittonen, L., Laitinen, T., \& MakiTorkko, N. (2003). Cardiovascular risk factors in childhood and carotid artery intima-media thickness in adulthood: The Cardiovascular Risk in Young Finns Study. Journal of the American Medical Association, 290, 2277-2283.

Ravaja, N., Keltikangas-Järvinen, L., \& Keskivaara, P. (1996). Type A factors as predictors of changes in the metabolic syndrome precursors in adolescents and young adults-A 3-year follow-up study. Health Psychology, 15, 18-29.

Roberts, B. W., \& Bogg, T. A. (2004). Longitudinal study of the relationships between conscientiousness and the social-environmental factors and substanceuse behaviors that influence health. Journal of Personality, 72, 325-354.

Rønsen, M. (2004). Fertility and public policies - Evidence from Norway and Finland. Demographic Research, 10, 143-170.

Sih, A., Bell, A., \& Johnson, J. C. (2004). Behavioral syndromes: An ecological and evolutionary overview. Trends in Ecology and Evolution, 19, 372-378.

Symons, D. (1987). If we're all Darwinians, what's the fuss about? In C. Crawford, D. Krebs, \& M. Smith (Eds.), Sociobiology and psychology (pp. 121-146). Hillsdale, NJ: Erlbaum.

Vikat, A. (2004). Women's labor force attachment and childbearing in Finland. Demographic Research, 3, 177-212.

Vining, D. R., Jr. (1986). Social versus reproductive success: The central theoretical problem of human sociobiology. Behavioral and Brain Sciences, 9, 167216.

Wolf, T. M., Sklov, M. C., Wenzl, P. A., Hunter, S. M., \& Berenson, G. S. (1982). Validation of a measure of type A behavior pattern in children: Bogalusa Heart Study. Child Development, 53, 126-135. 
